\title{
The Study on the Translation of Anti-Epidemic TCM Drug Instructions from the Perspective of Skopos Theory
}

\author{
Dan $\mathrm{Li}^{1}$ Yulei Shen ${ }^{1}$ Hongling Que ${ }^{1, *}$
}

\author{
${ }^{1}$ School of Foreign Languages, Hubei University of Chinese Medicine, Wuhan, Hubei 430065, China \\ *Corresponding author. Email: 47407180@qq.com
}

\begin{abstract}
Traditional Chinese medicine (TCM) carries the experience and theoretical knowledge of Chinese people in fighting against diseases. Since the outbreak of COVID-19, TCM has been widely used in China and some other countries for epidemic prevention and control. Against the current international background, the introduction of TCM to the outside world is in urgent need. Thus, the translation of TCM is of great significance. However, due to its professionality and cultural differences, there are some difficulties in the process of translation. Translators not only need to accurately convey information in original text, but also need to overcome cultural barriers and make translation smoother and easier to be understood by target readers. In order to seek effective translation strategies and improve the quality of TCM translation, this thesis analyzes the bilingual version of Instruction for LIAN HUA QING WEN Capsule issued by China-Philippines TCM Center and the Diagnosis and Treatment Protocol for COVID-19 (Trial Version 7) translated by Beijing University of Chinese Medicine, with a view to improving the quality of TCM translation and promoting the international exchange of TCM.
\end{abstract}

Keywords: anti-epidemic, TCM drug instructions, translation, skopos theory

\section{INTRODUCTION}

In this year's battle against novel coronavirus (COVID-19), TCM has been widely used in China and some other countries for epidemic prevention and control. Official figures showed that 91.6 percent of the patients in Hubei province and 92.4 percent of patients nationwide have been treated with TCM. The Diagnosis and Treatment Protocol for COVID-19 was shared to other countries. For translator, it's crucial to translate TCM Treatment accurately and achieve effective communication.

In this thesis, the author collects and analyzes the bilingual version of Instruction for LIAN HUA QING WEN Capsule issued by China-Philippines TCM Center and Diagnosis and Treatment Protocol for COVID-19 (Trial Version 7) translated by Beijing University of Chinese Medicine. Some of drugs mentioned in it have been listed into "three formulas and three medicines", such as LIAN HUA QING WEN Capsule, Xuebijing Injection and Qingfei Paidu Decoction, which has been proved to

*Fund: The Project of Research on Education in Hubei University of Chinese Medicine in 2018 (2018b13). be effective in treating the infection of COVID-19 according to the State Administration of Traditional Chinese Medicine.

TCM contains a lot of professional medical words, which requires translators to understand the professional knowledge involved in the original text and master relevant basic knowledge. Besides, translation is a culture exchange activity. Different people have different etiquette, customs, communication methods and language expression habits. Therefore, translators need to fully consider cultural differences to avoid cultural conflicts and enable target readers to understand the translation easily.

This thesis aims at providing effective translation strategies for the C-E translation of antiepidemic drug instructions. After analyzing the characteristics of bilingual instructions, the author puts forward some translation skills by cases study under the guidance of skopos theory. 


\section{ChaRACTERISTICS OF THE COLLECTED ANTI-EPIDEMIC DRUG INSTRUCTIONS}

The feature of Instruction for LIAN HUA QING WEN Capsule can be studied from two aspects: the language characteristic and syntactic features.

As for the language characteristic, first, there are a lot of professional words in drug instructions. Second, common words used in drug instructions have their professional meanings. Third, the extensive use of nouns. Fourth, for the sake of simplicity, the use of abbreviations has become an obvious feature of English drug instruction. (Lin Shengqu, 2013: 222-223).

As for the syntactic features, first of all, present indefinite tense and present perfect tense are commonly used. These two tenses are used to describe characteristics, pharmacological action, indications, dosage and precautions, etc. Second, passive voice is commonly used. For example, part of the application of Qingfei Paidu Decoction is expressed in this way: "It should be used reasonably with the consideration of the actual conditions of critically ill patients". Third, using conditional sentence. Fourth, a large number of imperative sentences are used in drug instructions. As imperative sentence gives people a sense of instruction and command, therefore, it is suitable to be used to provide consumer some authoritative information. For example, the storage of LIAN HUA QING WEN Capsule is as follows: "Preserve in tightly closed container, stored in a cold and dry place".

The content of Diagnosis and Treatment Protocol for COVID-19 (Trial Version 7) is mainly composed of symptom, clinical manifestation, recommended formula, the basic formula and administration, which is slightly different from the common structure of drug instructions.

According to the severity of the disease and different symptoms in different periods, the TCM treatment recommends corresponding prescriptions with Chinese medicine characteristics, which embodies the philosophy of TCM syndrome differentiation.

\section{A BRIEF INTRODUCTION OF SKOPOS THEORY}

Hans Vermeer, the student of Katharine Reiss, developed the main content of skopos theory. Vermeer believes that the purpose determines the translation strategies to be used.

The skopos theory has three principles. They are skopos rule, coherence rule and fidelity rule. The skopos rule means that purpose determines action.
The coherence rule means that the translation must be understandable and meaningful in the culture of target language, which requires translator to consider the target' knowledge and culture background. The fidelity rule requires the translator to be honest and loyal and the original information should be accurately conveyed to target reader. "In the relationship among three rules, fidelity rule is considered subordinate to coherence rule, and both are subordinate to skopos rule." (Zhang Lili, 2016: 1220).

\section{TRANSLATION STRATEGIES UNDER THE GUIDANCE OF SKOPOS THEORY}

\section{A. Translation strategies under the guidance of skopos rule}

There are three possible kinds of purpose in the field of translation. In general, "purpose" refers to the communicative purpose in the translation of drug instructions, that is to convey the original information effectively so that the recipient can understand drug instructions and the medicine can be used correctly. (Kang Demei, 2011: 102)

1) Amplification: Sometimes, it is necessary to add words or phrases in translation to directly express the implied meaning in original text and make the target text more understandable.

- Example 1

Source Text:

\section{【适应症】}

清壆解毒，宣肺泄热。用于治疗流行性感冒属热毒袭肺 证，症见：发热或高热，恶寒，肌肉酸痛，鼻塞流涕，咳嗽 ，头痛，咽干咽痛，舌偏红，苔黄或黄淢等。

(The Chinese version of the indication of LIAN HUA QING WEN Capsule)

Translation:

[Indications]

It clears away plague and detoxifies, relieves lung heat as TCM theory. Used for treating common colds or influenza with syndrome of heat toxin attacking lungs; The signs and symptoms presented are fever or high fever, chills, muscle aches, nasal congestion, runny nose, cough, headache, dry throat, red tongue, yellow or greasy fur etc.

(Translation from China-Philippines TCM Center)

\section{Analysis:}

Due to the differences between Chinese and English language structures, Chinese sentences are characterized by four-character phrases and the 
grammatical structure is relatively loose. Therefore, we add subject "It" in the translation to make the sentence structure more complete and the target text more understandable.

2) Omission: Although some words and phrases are indispensable to form the complete meaning of the original text, they are unnecessary in the target text. Therefore, the translator should delete those unnecessary words or phrases to make translation conform to the language habits of English.

- Example 2

Source Text:

\section{【注意事项】}

\section{请将本品放在儿童不能接触的地方。}

(The Chinese version of the precaution of LIAN HUA QING WEN Capsule)

Translation:

[Precautions]

Please keep this product out of the reach of children.

(Translation from China-Philippines TCM Center)

Analysis:

In this case, the original text is an imperative sentence. If we literally translate it into "please put this product in the place that children can't reach", it looks lengthy. Therefore, we delete words that do not in line with the target language's habits to avoid redundancy. By doing so, the meaning of the original text is expressed in a concise and clear way.

3) Liberal translation: The liberal translation enables translators to effectively convey original information without being bound to the form of original text. This type of translation method conforms to skopos rule and helps target readers to understand unique culture contained in original text.

\section{- Example 3}

Source Text:

临床表现：发热，乏力，周身酸痛，咳嗽，咯痰，胸紧 憋气，纳呆，恶心，呕吐，大便粘淢不爽。舌质淡胖齿痕或 淡红，苔白厚腐淢或白淢，脉濡或滑。

[The Chinese version of Diagnosis and Treatment Protocol for COVID-19 (Trial Version 7)]
Translation:

Clinical manifestation: fever, fatigue, generalized body aches, cough, expectoration, chest tightness and labored breathing, poor appetite, nausea, vomiting and sticky stool, pale enlarged tongue with tooth marks or light red tongue and coating which is white, thick, curd like, and greasy or white and greasy, and soggy of slippery pulse.

(The English version translated by Beijing University of Chinese Medicine)

\section{Analysis:}

Due to the specialty of TCM terms and the difficulty in understanding the language, it is difficult to translate TCM into English. The translator needs to understand the meaning of the original text accurately, and then he/she can express the connotation of the original text with simple and clear words in target language. In this example, "纳 呆" is translated into "poor appetite" rather than "dull".

\section{B. Translation strategies under the guidance of the coherence rule}

The coherence rule means that the translation must be understandable and meaningful in the culture of target language. In order to express the idea of original text accurately and smoothly, the translator must make translation conform to the language habit of target reader (Li Shujie, 2008: 38).

1) Word order reorganization: Chinese is usually expressed according to the sequence of events, while English is flexible in word order, and the clause indicating time, place, condition etc. can be placed before or after the main sentence in English. Therefore, when translating, the word order should be adjusted properly to make translation coherent

- Example 4

Source Text:

推荐中成药：血必净注射液、热毒宁注射液、痰热清注 射液、醒脑静注射液、参附注射液、生脉注射液、参麦注射 液。功效相近的药物根据个体情况可选择一种，也可根据临 床症状联合使用两种。中药注射剂可与中药汤剂联合使用。

[The Chinese version of Diagnosis and Treatment Protocol for COVID-19 (Trial Version 7)]

Translation:

Recommended Chinese patent medicines: Xuebijing injection, Reduning injection, Tanreqing injection, Xingnaojing injection, Shenfu injection, Shengmai injection, and Shenmai injection. Drugs 
with similar effects can be selected according to individual conditions, or can be used in combination according to clinical symptoms. Traditional Chinese medicine injection can be used together with TCM decoction.

(The English version translated by Beijing University of Chinese Medicine)

Analysis:

In Chinese, most modifiers are put before the modificand, but in English, the most important information should be put on the front of the sentence and the other components are behind. Therefore, in this example, the key word "drug" is put at the beginning of a sentence, and then use the preposition "with" to connect modifiers.

- Example 5

Source Text:

\section{【服法】}

传统中药饮片，水煎服。每天一付，早晚各一次(饭后四 十分钟)，温服，三付一个疗程。

[The Chinese version of the administration of Qingfei Paidu Decoction in the Chinese version of Diagnosis and Treatment Protocol for COVID-19 (Trial Version 7)]

Translation:

Administration:

Traditional Chinese herbal pieces in decoction. One package per day. Take warm twice (40 minutes after meal in the morning and evening). One course of treatment is for three packages.

(The English version translated by Beijing University of Chinese Medicine)

Analysis:

In this case, the translation of "温服" is expressed before "早晚各一次(饭后四十分钟)". In English, the most important information usually precedes additional information, and the medication method is more important to patients than medication frequency and time; therefore, it is reasonable to change word order.

2) Transformation of active voice and passive voice: The sentence structure used in drug package insert is relatively simple and clear. The passive voice is mainly used in the introduction of drug usage and dosage, drug properties. Passive sentences can be used to describe some objective things through letting science and facts explain the truth, rather than using a person's subjective opinions.
- Example 6

Source Text:

【注意事项】

根据中国卫健委发布的《新型冠状病毒感染的肺炎诊疗 方案(试行第七版)》，连花清瘟胶囊在新冠肺炎的常规治疗 中，可用于轻型、普通型引起的发热、咳嗽、乏力。

(The Chinese version of LIAN HUA QING WEN Capsule)

Translation:

[Precautions]

According to the National Health Commission of the People's Republic of China, LIAN HUA QING WEN Capsule can be used in the routine treatment of COVID-19, which is commonly presented as fever, cough and fatigue. Center)

(Translation from China-Philippines TCM

\section{Analysis:}

In this example, "用于" in original text is an active phrase, however, in the target text, it is translated into a passive phrase by using verb "be" and the passive voice of the predicate "use" to show passive meaning.

3) Transformation of affirmative and negative sentences: Negation refers to the negative words or components such as "never, no, not, non-, un- and less" in English and "不、没、无、否" in Chinese.

- Example 7

Source Text:

\section{【注意事项】}

请将本品放在儿童不能接触的地方。

(Precaution of LIAN HUA QING WEN Capsule)

Translation:

[Precautions]

Please keep this product out of the reach of children.

(Translation from China-Philippines TCM Center)

\section{Analysis:}

In this example, it can be found that there is a symbolic negative word "不" in original text, but in target text, there is no word indicating negative meaning. When translating, we transform the negative sentence "不能..." into an affirmative sentence that can express same meaning. 


\section{Translation strategies under the guidance of the fidelity rule}

Since translation is an act of information communication, there must be some kind of relationship with the original source text. Vermeer calls this relationship intertextual coherence and fidelity. (Zhao Yushan and Jiang Yanwen, 2014: 10).

1) Literal translation: Literal translation is the most common used translation method used to convey the original information to the greatest extent, which helps to maintain both content and form of original text.

- Example 8

Source Text:

\section{寒湿郁肺证 湿热蕴肺证}

[The Chinese version of Diagnosis and Treatment Protocol for COVID-19 (Trial Version 7)]

Translation:

Cold-damp constraint in the lung pattern

Damp-heat accumulation in the lung pattern

(The English version translated by Beijing University of Chinese Medicine)

Analysis:

In this example, "寒湿、湿热" are respectively translated into "Cold-damp and Damp-heat". The source text and target text are equal in both meaning and sentence form.

2) Transliteration: This translation strategy can convey cultural characteristics of the original text and enrich language expressions of the target language (Kuang Zhanghong and Zhu Yunyun, 2009: 314), which is in line with the fidelity rule of bearing relationship with the corresponding source text.

\section{- Example 9}

Source Text:

【成份】

连翘、金银花、多麻黄、炒苦杏仁、石膏、板蓝根、绵 马贯众、鱼腥草、广雚香、大黄、红景天、薄荷脑、甘草。 辅料为玉米淀粉。

(The Chinese version of the component of LIAN HUA QING WEN Capsule)

Translation:

[Composition]
Lianqiao (Forsythia), Jinyinhua (Flos Lonicerae), Mahuang (Herba Ephedrae), Kuxinren (Semen Armeniacae Amarum), Shigao (Gypsum Fibrosum), Banlangen (Radix Isatidis), Guanzhong (Rhizoma Dryopteris Crassirhizomae), Yuxingcao (Herba Houttuyniae), Huoxiang (Herba Agastachis), Dahuang (Radix et Rhizoma Rhei), Hongjingtian (Rhodiola Rosea), menthol, licorice. The excipients are corn starch. Center)

(Translation from China-Philippines TCM

\section{Analysis:}

When it is difficult to find the corresponding translation of Chinese medicine names in English, we choose to use transliteration method, i.e., using Chinese Pinyin. In this way, we can not only retain the cultural characteristics of the original text, but also help to expand the vocabulary of the target language and promote the cultural exchange between China and the West.

\section{CONCLUSION}

In conclusion, this paper studied on the translation of anti-epidemic drug instructions from the perspective of skopos theory and the following conclusion can be drawn.

First, since large quantities of professional words are identified in the translation of drug instructions, it is essential for translators to develop their ability to use language, especially their competence of using medical vocabulary.

Second, some translation errors of drug instructions are attributed to the translators' faulty or partial knowledge of culture and language habits in English. Therefore, translators should bridge the gap between Chinese and English by fully understanding their differences in languages, cultures and ways of thinking.

Third, traditional Chinese medicine has been widely used in the prevention, treatment and rehabilitation of novel coronavirus pneumonia. For translator, it is meaningful to choose appropriate translation strategies and make translation accurate and coherent for target reader. It can not only achieve effective communication, but also make contribution to promoting traditional Chinese medicine.

Due to the author's limited knowledge, this thesis can't study the translation of anti-epidemic TCM drug instructions completely and there must be some details worth further research and discussion.

All in all, it is hoped that this study will be helpful to the translation of Chinese drug instructions. I believe there will be more reflections 
from different perspectives about this topic and the research content will be more comprehensive and in-depth in the future.

\section{References}

[1] Zhang, Lili. Study of Business English Translation Based on the Three Rules of Skopos Theory [P]. Proceedings of the 2016 International Conference on Economy, Management and Education Technology, 2016: 1220.

[2] Kang, Demei. On the Translation of Chinese Patent Medicine Instructions from the Perspective of Skopos Theory [J]. Journal of Weifang Educational College, 2011, 24(01): 102.

[3] Li, Shujie. Three Principles of Skopostheorie and Translation of Drug Instructions [J]. Journal of Liaoning Medical College (Social Science Edition), 2008(04): 38.

[4] Lin, Shengqu. Drug Instructions and their Translation Strategies from the Perspective of Skopos Theory [J]. College English (Academic Edition), 2013, 10(02): 222223.

[5] Zhao, Y. and Y. Jiang. Translation Techniques of Chinese Union Version: From the Perspective of Skopos Theory [J]. Canadian Social Science, 2014, 10(3): 10.

[6] Kuang, Z. and Y. Zhu. On Domestication and Foreignization from Teleology $[\mathrm{J}]$. Journal of Inner Mongolla Agricultural University (Social Science Edition), 2009, 11(02): 31 . 